\title{
Leptin, insulin and thyroid hormones in a cohort of Egyptian obese Down syndrome children: a comparative study
}

Sohier Yahia ${ }^{1}$, Reham M EL-farahaty², Amany K El-Hawary ${ }^{*}$, Mona A El-hussiny², Hanaa Abdel-maseih², Faeza El-Dahtory ${ }^{3}$ and Abdel-Hady El-Gilany ${ }^{4}$

\begin{abstract}
Background: Obesity is a major worldwide health problem. It is commonly observed in Down syndrome individuals than in the general population. The reason for increased risk of obesity in DS is unclear.

The current study was designed to clarify differences in some obesity- related hormones in a group of prepubertal Down syndrome children.

Methods: Thirty six Egyptian children with Down syndrome were enrolled in this study, divided according to their body mass index (BMI) into 23 obese and13 non obese. Another group of 43 non Down children were recruited, they were divided according to their BMI into 20 patients having simple obesity and 23 non obese, as control groups. Fasting blood samples were collected for estimation of fasting blood glucose (FBG), insulin, leptin, free thyroxin $\left(\mathrm{FT}_{4}\right)$, thyroid stimulating hormones (TSH) and creatine kinase (CK). Insulin resistance was assessed by Homeostasis Model Assessment method (HOMA-IR). The ratio of leptin to BMI (LEP/BMI) was used as an index of leptin resistance.

Results: Median values of FBG, insulin, and HOMA-IR were significantly higher in Down versus non Down groups, while median values of leptin and leptin resistance were non-significantly different among Down versus non Down groups. Median TSH values were non- significantly different between obese Down and obese non Down. Although the median values of TSH and FT4 were within normal range in Down groups, four cases of subclinical hypothyroidism were encountered. Leptin levels were correlated with insulin and IR but not with TSH in Down groups.

Conclusion: Increased circulating leptin, a marker of leptin resistance in obese children with Down syndrome seems to be similar to that in children with simple obesity. Elevated FBG and insulin in obese Down children highlights the presence of early IR. Associated myopathy evidenced by mildly elevated CK levels could be an added factor for obesity in such group of patients.
\end{abstract}

Keywords: Down syndrome, Obesity, Leptin, Leptin resistance, Insulin resistance

\footnotetext{
* Correspondence: amany.hawary.hawary10@gmail.com

'Department of Pediatrics, Faculty of Medicine, Mansoura University Children Hospital, Mansoura, Egypt

Full list of author information is available at the end of the article
} 


\section{Background}

Down syndrome (DS, trisomy 21) is the most common chromosomal abnormality affecting live-born infants. Children with DS demonstrate an increased risk of developing various endocrine disorders, such as hypothyroidism, diabetes mellitus and childhood obesity [1]. Unique characteristics of this syndrome such as reduced resting metabolic rates [2] or decreased physical activity [3] and increased risk of diabetes or hypothyroidism [4] may play a role in the development of obesity. In addition, children with DS may have a tendency to overeat, since the cerebral regions that are responsible for weight regulation may be damaged [5,6] moreover, there is incapacity to do long physical exercise in DS individuals because the effort can be quickly perceived as painful, difficult and without sense for them, which contributes to adoption of a sedentary lifestyle [7].

Obesity is known to increase the risk of morbidity and mortality in DS persons [8]. Obesity is characterized by an increase of adipose tissue mass [9]. Adipocytes secrete leptin hormone, which acts in the hypothalamus to suppress appetite and control body weight [10]. In addition, insulin regulates energy homeostasis through control of appetite and energy expenditure [11]. Both hormones rise in direct proportion to adipose mass, they cross blood brain barrier and have receptors in the arcuate nucleus [12].

Although leptin production is positively correlated with the percentage of body fat, it is postulated that obese individuals, with hyperleptinemia, have some degree of leptin resistance [10]. It is unclear whether this mechanism is similar in children with DS.

\section{The aim of the work}

The current study was designed to clarify differences in some obesity- related hormones in a group of prepubertal Down syndrome children.

\section{Methods}

The present study was conducted on two groups: group I, comprised 36 children having DS confirmed as trisomy 21 by chromosomal study their age ranged from 2 to 10 years. All were living within their families and were of same socioeconomic class, they were not assigned for special diet regimen. They were recruited from outpatient clinic of Pediatric Genetic Unit, Mansoura University Children Hospital; they were enrolled in physical and speech therapy programs to help their motor skills and language development. They were divided according to BMI into; non obese Down (NOD) group of 13 cases, of whom 7 males and 6 females with BMI percentiles $>5^{\text {th }}$ to $\leq 85^{\text {th }}$, their ages ranged from 2 to 8 years, and the obese Down (OD) group of 23 cases, of whom 13 males and 10 females, their age ranged from 2.5 to 10 years, with BMI percentiles $>95^{\text {th }}$. Group II comprised 43 children, without DS to act as a control group. They were divided according to BMI into; 20 obese non Down patients (OND) including 12 males and 8 females to represent simple obesity they were recruited from Endocrinology unit, Mansoura University Children Hospital. Their age ranged from 2.8 to 11 years, and 23 non obese non Down (NOND) healthy children including 12 males and 11 females, their age ranged from 2 to 10 years. The study was approved by the research ethics committee of Mansoura University. All groups are subjected to thorough history and clinical examination including the presence of acanthosis nigricans. Anthropometric data were collected as part of an ongoing research program ascertaining standing height to the nearest $0.1 \mathrm{~cm}$ in bare feet using portable Harpender stadiometer and weight to the nearest $0.1 \mathrm{~kg}$ using digital weight scale, the measurements were repeated twice and the average was recorded. BMI was calculated for groups as weight $(\mathrm{kg})$ divided by height $(\mathrm{m})$ squared [13]. We excluded children who had started pubertal development according to Tanner and Whitehouse staging (1976) [14] to avoid hormonal changes induced by puberty. Patients having chronic conditions affecting growth or energy balance and children who already were taking thyroxine, corticosteroids or immunosuppressive drugs were excluded.

Laboratory data: Blood samples were collected after a-12 hours overnight fast for estimation of fasting blood glucose (FBG), insulin, leptin, Thyroid stimulating hormone (TSH), Free thyroxin $\left(\mathrm{FT}_{4}\right)$ and creatine kinase (CK). FBG was estimated by liquizyme GOD- PAP supplied by Human, Germany [15]; serum insulin by chemilumeinescent immunometric assay using IMMULITE $^{\circledR}$ 1000 supplied by Siemenes Healthcare Diagnostics, USA [16], serum leptin by enzyme-linked immunosorbent assay (ELISA) supplied by DRG GmbH, Germany [10] and serum CK levels using CK-NAC liquid, UV kinetic method (Human,Germany) [15]; and serum TSH and $\mathrm{FT}_{4}$ concentrations by electrochemiluminescence immunoassay (ECLIA) using Elecsys 2010, Roch Diagnostics $\mathrm{GmbH}$, Germany [17]. Insulin resistance (IR) was calculated according to homeostasis model assessmentestimated insulin resistance (HOMA-IR), through the formula: FBG $(\mathrm{mmol} / \mathrm{L}) \mathrm{x}$ fasting insulin $(\mu \mathrm{IU} / \mathrm{ml}) / 22.5$ [18]. The ratio of leptin to BMI (LEP/BMI) was used as an index of leptin resistance (Leptin- R). This index measures leptin levels while controlling for the contribution of BMI [19].

\section{Statistical analysis}

Data were analyzed using SPSS statistical package version 16. Categorical variable (sex) was presented as number and percent. Chi square test was used for comparison between groups. Numerical variables were tested for normality by 
Kolmogorov-Smirnov test and found to be non parametric in distribution. So Kruskal Wallis was used for comparison between four groups while, Mann Whitney was used for comparison between two groups. Spearman's correlation coefficient was used to test the correlation between variables within each group of patients. $\mathrm{P} \leq 0.05$ was considered to be statistically significant.

\section{Results}

Table 1 showed comparison between studied groups regarding age, sex, FBG, obesity- related hormones and
CK. Regarding age and sex there were no significant difference between four groups $(P=0.160,0.962)$.

Considering Down groups; OD group showed significantly higher median values of FBG, insulin, HOMA-IR, leptin and leptin-R compared with NOD group $(\mathrm{P}<$ 0.001 ), while no significant differences as regard $\mathrm{TSH}$, $\mathrm{FT}_{4}$ and $\mathrm{CK}$.

Considering the two obese groups, OD group showed significantly higher median values of FBG, insulin, HOMA$\mathrm{IR}, \mathrm{FT}_{4}$ and $\mathrm{CK}$ compared with OND group ( $\left.\mathrm{p}<0.001\right)$. The increase in median values of FT4 and CK were within

Table 1 Comparison between studied groups regarding age, sex, FBG, some obesity- related hormones and CK

\begin{tabular}{|c|c|c|c|c|c|}
\hline \multirow[t]{3}{*}{ Parameters } & \multicolumn{5}{|c|}{ Groups } \\
\hline & \multirow{2}{*}{$\begin{array}{c}\mathrm{OD} \\
\mathrm{n}=23\end{array}$} & \multirow{2}{*}{$\begin{array}{l}\text { NOD } \\
n=13\end{array}$} & \multirow{2}{*}{$\begin{array}{l}\text { OND } \\
n=20\end{array}$} & \multirow{2}{*}{$\begin{array}{c}\text { NOND } \\
\mathrm{n}=23\end{array}$} & \multirow[t]{2}{*}{$\mathrm{P}^{\#}$} \\
\hline & & & & & \\
\hline \multicolumn{6}{|l|}{ Age (years) } \\
\hline Median & 5 & 4 & 6 & 5 & \multirow[t]{2}{*}{0.160} \\
\hline Range & $2.5-10$ & $2-8$ & $2.8-11$ & $2-10$ & \\
\hline \multicolumn{6}{|l|}{ Sex } \\
\hline Male & 13(56\%) & $7(53 \%)$ & $12(60 \%)$ & $12(52 \%)$ & \multirow[t]{2}{*}{0.96} \\
\hline Female & $10(43 \%)$ & $6(46 \%)$ & $8(40 \%)$ & $11(48 \%)$ & \\
\hline \multicolumn{6}{|l|}{ FBG $(\mathrm{mmo} / \mathrm{l})$} \\
\hline Median & $6.2^{\mathrm{ab}}$ & $5.2^{\mathrm{ac}}$ & $5.6^{b}$ & $4.6^{c}$ & \multirow[t]{2}{*}{$<0.00$} \\
\hline Range & $5.2-6.8$ & $4.4-6.3$ & $2.7-6.10$ & $4-5.2$ & \\
\hline \multicolumn{6}{|c|}{ Insulin (uU/ml) } \\
\hline Median & $20^{\mathrm{ab}}$ & $7^{\text {ac }}$ & $10.9^{b}$ & $3.8^{c}$ & \multirow[t]{2}{*}{$<0.00$} \\
\hline Range & $9-56$ & $4-10$ & $4.6-18.5$ & $2-6$ & \\
\hline \multicolumn{6}{|l|}{ HOMA-IR } \\
\hline Median & $5.8^{a b}$ & $1.56^{a c}$ & $2.58^{b}$ & $0.77^{c}$ & \multirow[t]{2}{*}{$<0.00$} \\
\hline Range & $2.2-8.35$ & $0.9-2.57$ & $0.77-4.88$ & $0.38-1.38$ & \\
\hline \multicolumn{6}{|c|}{ Leptin (ng/ml) } \\
\hline Median & $18^{a}$ & $3^{a}$ & 18.25 & 3 & \multirow[t]{2}{*}{$<0.00$} \\
\hline Range & $11-36$ & $1.8-10$ & $10.4-45.7$ & $1.9-7.0$ & \\
\hline \multicolumn{6}{|l|}{ leptin R } \\
\hline Median & $0.68^{a}$ & $0.21^{a}$ & 0.67 & 0.195 & \multirow[t]{2}{*}{$<0.00$} \\
\hline Range & $0.4-1.26$ & $0.13-0.46$ & $0.45-1.2$ & $0.146-0.304$ & \\
\hline \multicolumn{6}{|l|}{$\overline{\text { TSH (uU/ml) }}$} \\
\hline Median & 3 & $2.8^{c}$ & 3.3 & $1.3^{c}$ & \multirow[t]{2}{*}{$<0.00$} \\
\hline Range & $0.85-7.30$ & $1-5.7$ & $0.7-2.7$ & $0.4-3.0$ & \\
\hline \multicolumn{6}{|l|}{ FT4 (pmol/L) } \\
\hline Median & $16^{b}$ & 16.2 & $12^{b}$ & 14 & \multirow[t]{2}{*}{$<0.00$} \\
\hline Range & $12-22$ & $13-20$ & $10.4-14.8$ & $12.5-15$ & \\
\hline \multicolumn{6}{|l|}{$\overline{\mathrm{CK}(\mathrm{U} / \mathrm{L})}$} \\
\hline Median & $60^{b}$ & $50^{c}$ & $29^{b}$ & $30^{c}$ & \multirow[t]{2}{*}{$<0.001$} \\
\hline Range & $12-193$ & $35-130$ & $18-47$ & $24-50$ & \\
\hline
\end{tabular}

OD: Obese Down. NOD: Non obese Down.

OND: Obese non Down. NOND: Non obese non Down.

\#: Kruskal wallis test was used except for association with sex, Chi square test was used.

a: Significant $P_{(M W)}<0.05$, comparing OD Vs NOD groups.

b: Significant $\mathrm{P}_{(M w)}<0.05$, comparing OD Vs OND groups.

c: Significant $P_{(M W)}<0.05$, comparing NOD Vs NOND groups. 
Table 2 Correlations between some studied parameters in each group

\begin{tabular}{|c|c|c|c|c|c|c|c|c|}
\hline \multirow[t]{2}{*}{ Parameters } & \multicolumn{2}{|c|}{ OD } & \multicolumn{2}{|c|}{ NOD } & \multicolumn{2}{|c|}{ OND } & \multicolumn{2}{|c|}{ NOND } \\
\hline & $r$ & $\mathbf{P}$ & $\mathrm{R}$ & $p$ & $r$ & $p$ & $r$ & $p$ \\
\hline \multicolumn{9}{|l|}{ Age: } \\
\hline and leptin & 0.913 & $<0.001$ & 0.557 & 0.048 & 0.510 & 0.021 & 0.947 & $<0.001$ \\
\hline and leptin -R & 0.925 & $<0.001$ & 0.089 & 0.772 & 0.440 & 0.052 & 0.792 & $<0.001$ \\
\hline and Insulin & 0.575 & 0.004 & 0.305 & 0.310 & 0.310 & 0.183 & 0.795 & $<0.001$ \\
\hline \multicolumn{9}{|l|}{ Leptin: } \\
\hline and insulin & 0.619 & 0.002 & 0.722 & 0.005 & 0.336 & 0.148 & 0.775 & $<0.001$ \\
\hline and HOMA-IR & 0.608 & 0.002 & 0.626 & 0.022 & 0.402 & 0.079 & 0.806 & $<0.001$ \\
\hline and leptin- $R$ & 0.969 & $<0.001$ & 0.709 & 0.007 & 0.985 & $<0.001$ & 0.899 & $<0.001$ \\
\hline and TSH & 0.170 & 0.438 & 0.472 & 0.104 & 0.222 & 0.347 & 0.645 & 0.001 \\
\hline CK and TSH & 0.636 & 0.001 & 0.194 & 0.524 & 0.371 & 0.108 & 0.433 & 0.039 \\
\hline
\end{tabular}

reference range, but no significant differences as regard leptin and leptin-R between both groups. At the same time, among the two normal BMI groups ( $>5$ to $\leq 85$ percentiles), NOD group showed significantly higher but still within reference range median values of FBG, insulin, HOMA-IR, $\mathrm{TSH}, \mathrm{FT}_{4}$ and $\mathrm{CK}$ compared with NOND group ( $\mathrm{P}=$ $0.003,<0.001)$, while no significant differences as regard leptin and leptin- $\mathrm{R}$ were present between both groups.

Table 2 showed correlations between studied parameters in each group. Significant positive correlations were observed between age and each of leptin, leptin- $R$ and insulin in both OD and NOND groups and only between age and leptin in OND group. Also significant positive correlation were observed between leptin and each of insulin, HOMA-IR and leptin resistance in OD, NOD and NOND groups, while in OND group significant positive correlation were observed only between leptin and leptin $-R$, but no correlation were found between leptin and TSH . As regard CK there were significant positive correlation with TSH in both OD and NOND groups.

\section{Discussion}

The main findings of the present study are the association between hyperinsulinemia, impaired fasting glucose and obesity in obese Down children, that could make them at higher risk to develop IRS. Also there is elevation of leptin and leptin- $\mathrm{R}$ median values in both OD and NOD groups with normal thyroid profile in down children. However four cases of subclinical hypothyroidism associated with CK above $90 \mathrm{U} / \mathrm{L}$ values were observed. This study was one of the few to report median and range values of some hormones related to obesity in a cohort of Egyptian DS obese and non obese prepubertal children.

\section{IR in children with DS}

One of the characteristics of the person with trisomy 21 is the propensity for becoming obese [2]. IR is the most common metabolic alteration related to obesity [20]. Considering the upper limit of FBG up to $5.55 \mathrm{mmol} / \mathrm{L}$ [21], normal fasting range for insulin varies from 5 to 15 $\mu \mathrm{IU} / \mathrm{ml}[22]$ and fasting insulin greater than $15 \mu \mathrm{IU} / \mathrm{ml}$ indicated IR [12]. This study showed significant higher median values of FBG, insulin and IR (assisted by HOMA-IR) in Down (OD, NOD) versus non Down (OND, NOND) groups with highest median values in OD group. This could be attributed to high levels of adipose tissue (which is more central than peripheral) in such children $[22,23]$ and the fact that central adiposity is more associated with IR [22]. Magge et al. [24] observed significantly higher percent body fat, non significantly higher insulin and glucose in children with DS than unaffected siblings, while no significant difference in HOMA-IR. It was suggested previously in small size study, (15 cases, including one prepubertal child with DS) that increased HOMA-IR and high rate of glucose production indicated presence of peripheral and hepatic IR in adolescent with DS [22].

Considering one of the two definitions of IR syndrome in children: [1] the presence of any three or more of hyperinsulinemia, overweight, high systolic blood pressure, high triglycerides, low HDL-C and impaired fasting glucose; and [2] the presence of hyperinsulinemia and at least two of the other five risk factors [25]. Our study reported an association between hyperinsulinemia, impaired fasting glucose and obesity in obese Down children, that could make them at higher risk to develop severe metabolic complications. In contrary Flore et al., 2008 [26] could not display IR in a group of young non obese adults with DS.

\section{Leptin, leptin-R \& obesity in DS children}

Considering leptin and leptin- $\mathrm{R}$, a higher median value of leptin in OD children was observed in this study, however, no significant difference in leptin and leptin - $R$ were observed between OD versus OND, indicating an 
increase in median leptin values, a marker of leptin resistance in obese children irrespective to the cause of obesity. This was in contrary to the suggestion of presence of genetic basis for obesity (three copies of chromosome 21) that might be a cause of more severe leptin resistance in DS [24]. Previously Considine et al. [10] concluded that obese individuals have higher leptin levels than normal weight individuals, and obesity is associated with leptin resistance. This belief is in harmony with our results that showed positive correlation between leptin and leptin- $\mathrm{R}$ in obese groups (OD, OND).

\section{Insulin leptin interrelationship}

Consistent with insulin/leptin arcuate nucleus of the hypothalamus axis, insulin and glucose appear to stimulate leptin secretion in adipocytes. In response, leptin decreases insulin secretion via direct action on leptin receptors in pancreatic B-cells while enhancing their actions and consequently improves whole body insulin sensitivity [27].

So, obesity promoted - hyperinsulinemia stimulates leptin release. Like other biological signaling pathways, leptin appears to regulate its own receptor signaling or increased central leptin results in reduced hypothalamic leptin receptor expression and leptin signaling. Hence, obesity promotes hyperleptinemia, which in turn self promotes leptin resistance and further obesity, making leptin resistance both a consequence and cause of obesity [27]

\section{Thyroid dysfunction in DS}

Thyroid dysfunction is highly prevalent in DS persons. The clinical symptoms and signs of both DS and hypothyroidism are overlapping to some extent e.g. hypotonia, mental retardation, growth failure, macroglosia, obesity etc. [28]. The presence of undetected hypothyroidism in children with DS could compound the problems in already compromised situation.

We observed significantly higher $\mathrm{FT}_{4}$ but not exceeding reference range ( $1-5$ years: $11.9-22.1 ; 6-10$ years: $11.5-$ $19.96 \mathrm{pmol} / \mathrm{L}$ ) [29] with no significant difference in TSH values in Down versus non Down groups. This was in contrary to previous data reported by Konings et al. [4] and Shaw et al. [28] who found higher mean TSH values $\left(6.5 \pm 1.3,5.4 \pm 2.9 \mathrm{mU} / \mathrm{l}\right.$ respectively) in face of normal $\mathrm{FT}_{4}$ or $\mathrm{T}_{4}$. They hypothesized that thyroid gland in children with DS needs an elevated TSH pressure to produce sufficient hormones [4]. However, we observed elevated serum TSH values with normal thyroxine levels in four cases, three in OD and one in NOD groups denoting subclinical hypothyroidism, associated with CK above 90U/1 [30].

\section{Hypotonia, CK \& associated myopathy in DS children}

Considering hypotonia as a risk factor for obesity in DS, we suggest that it could be associated with muscle breakdown. CK is considered the primary marker for muscle breakdown, in response to exercise, a portion of the population has exaggerated increases in CK [31,32]. Reasons for an exaggerated response are not fully understood but may reflect genetics [31], fiber type, an underlying myopathy, and/or some other environmental behavioral factors, including fitness level [33]. Furthermore variations in muscle mass have been proposed to account for interracial differences in total CK activity [34]. Our results showed significantly higher median CK value in OD compared with OND group. Also a positive correlation was found between CK and TSH in OD group. Associated myopathy either endocrine [35] (hypothyroid related myopathy) or infectious secondary to viral infection [36], strenuous physical activity [32] may be the underlying causes for these mildly elevated CK values and muscle weakness could be added to the hypotonia which is a part of genetic predisposition of the disease.

\section{Conclusions}

Increased circulating leptin, a marker of leptin resistance in obese Down children seems to be similar to that in children with simple obesity, this could point to an absence of genetic basis for more leptin resistance in such high risk population for obesity. The association between fasting hyperglycemia and hyperinsulinemia in obese children with DS indicates early IR, suggesting a possible genetic basis. Associated myopathy could be an added factor for obesity as proved by the mildly elevated CK values. Large sample size, studying other causes of DS and further genetic study are needed to prove the genetic role in this tendency for obesity in DS.

\section{Limitations}

The study was small in size, single center, cross sectional comparative study. It relied solely on BMI for age percentiles of Center of Disease Control and Prevention as an indicator of body fatness because it is simple, easily obtained than skin folds thickness, presence of standardized BMI curves and cut-off points defining overweight \& adiposity in childhood [37] and correlates well with DEXA [38]. Previous results, suggest that skin fold measurements may only slightly improve $(8 \%)$ the estimation of body fatness among children who are obese (BMI 295th CDC percentile) [39]. Furthermore it may help determine if an overweight child may have excess body fatness [39] and this group of children were not included in our study. Finally due to racial variation and poor inter- and intra- observer reliability skin fold thickness equations should be validated in each population and it is difficult to standardize [39]. While for waist circumference, no internationally accepted cut points for either the classification of obesity or presence of increased 
metabolic risk in children as in adult [25], furthermore, no data on population with DS can be found on this regard [40]. Body fat itself is not necessarily a precise measure of health risk. As stated by the recent AMA expert committee [41], "High levels of body fat are associated with increasing health risks. However, no single body fat value, whether measured as fat mass or as percentage of body weight, clearly distinguishes health from disease or risk of disease".

\section{Competing interests}

The authors declare that they have no competing interests.

\section{Authors' contributions}

SY conducted and draft the study, participated in its design and coordination and shared in clinical diagnosis and recruiting of patients. RME carried out laboratory studies participated in study design, shared in writing the manuscript and data acquisition. AKE participated in clinical diagnosis and recruiting of patients, shared in collection of data, drafting and reviewing the study. MAE and HA helped performing laboratory studies. FE performed the chromosomal study of patients. AHE performed statistical analysis. All authors read and approved the final manuscript.

\section{Author details}

'Department of Pediatrics, Faculty of Medicine, Mansoura University Children Hospital, Mansoura, Egypt. ${ }^{2}$ Department of Clinical Pathology, Faculty of Medicine, Mansoura University, Mansoura, Egypt. ${ }^{3}$ Cytogenetic Lab, Genetic Unit, Children Hospital, Mansoura University Children Hospital, Mansoura, Egypt. ${ }^{4}$ Department of Public Health, Faculty of Medicine, Mansoura University, Mansoura, Egypt.

Received: 27 January 2012 Accepted: 4 October 2012

Published: 15 October 2012

\section{References}

1. Grammatikopoulou MG, Manai A, Tsigga M, Tsiligiroglou-Fachantidou A, Galli-Tsinopoulou A, Zakas A: Nutrient intake and anthropometry in children and adolescents with Down syndrome - a preliminary study. Dev Neurorehabil 2008, 11(4):260-7.

2. Murray J, Ryan-Krause P: Obesity in children with Down syndrome: background and recommendations for management. Pediatr Nurs 2010, 36(6):314-9.

3. Whitt-Glover MC, O'Neill KL, Stettler N: Physical activity patterns in children with and without Down syndrome. Pediatr Rehabil 2006, 9(2):158-64.

4. Konings $\mathrm{CH}$, Van Trotsenburg AS, Ris-Stalpers C, Vulsma T, Wiedijk BM, De Vijider JJ: Plasma thyrotropin bioactivity in Down syndrome children with subclinical hypothyroidism. Euro J Endocrinol 2001, 144:1-4.

5. Luke A, Sutton M, Schoeller DA, Roizen NJ: Nutrient intake and obesity in prepubescent children with Down syndrome. J Am Diet Assoc 1996, 96:1262-7.

6. Reinehr T, Dobe M, Winkel K, Schaefer A, Hoffmann D: Obesity in Disabled Children and Adolescents An Overlooked Group of Patients. Dtsch Arztebl Int 2010, 107(15):268-75.

7. Bricout VA: Endocrine and autonomic nervous adaptations during physical exercise in Down syndrome. In Genetics and etiology of Down syndrome. Edited by Dey S: Tech publisher; 2011:236. Available from: http:// www.intechopen.com/books/genetics-and-etiology-of-down syndrome/ endocrine-and-autonomic-nervous-adaptations-during-physical-exercise-indown-syndrome, 2011.

8. Melville CA, Cooper SA, McGrother CW, Thorp CF, Collacott R: Obesity in adults with Down syndrome: a case-control study. Intellectual Disability Res J 2005, 49(2):125-33.

9. Cernkovich ER, Deng J, Bond MC, Combs TP, Harp JP: Adipose-specific disruption of signal transducer and activator of transcription 3 increases body weight and adiposity. Endocrinology 2008, 149(4):1581-90.

10. Considine RV, Sinha MK, Heiman ML, Kriauciunas A, Stephens TW, Nyce MR, et al: Serum immunoreactive leptin .concentrations in normal-weight and obese humans. N Engl J Med 1996, 334:292-5.
11. Lopaschuk GD, Ussher JR, Jaswal JS: Targeting intermediary metabolism in the hypothalamus as a mechanism to regulate appetite. Pharmacol Rev 2010, 62:237-264.

12. Ten S, Maclaren N: Insulin Resistance Syndrome in children. J Clin Endocrinol Metab 2004, 89(6):2526-39.

13. Myrelid A, Gustafsson J, Ollars B, Annerén G: Growth charts for Down's syndrome from birth to 18 years of age. Arch Dis Child 2002, 87:97-103.

14. Tanner JM, Whitehouse RH: Clinical longitudinal standards for height, weight, height velocity, weight velocity, and stages of puberty. Arch Dis Child 1976, 51:170-9.

15. Tietz NW: Clinical guide to laboratory tests. 3rd edition. Philadelphia: WB Saunders; 1995:268-73.

16. Reeves WG: Insulin antibody determination: theoretical and practical considerations. Diabetologia 1983, 24:399-403.

17. Nicoloff JT, Spencer CA: The use and misuse of the sensitive thyrotropin assays. J Clin Endoc Metab 1990, 71:553-58.

18. Matthews DR, Hosker JP, Rudenski AS, Naylor BA, Treacher DF, Turner RC Homeostasis model assessment:insulin resistance and $\beta$-cell function from fasting blood glucose and insulin concentrations in man. Diabetologia 1985, 28:412-19.

19. Lee JH, Reed DR, Price RA: Leptin resistance is associated with extreme obesity and aggregates in families. Int J Obes 2001, 25:1471-3.

20. Chiarelli F, Marcovecchio ML: Insulin resistance and obesity in childhood. Eurpean Journal of Endocrinology 2008, 159:s67-s74.

21. American Diabetes Association: Diagnosis and classification of Diabetes mellitus. Diabetes Care 2011, 34:562-s69.

22. Fonseca CT, Amaral DM, Ribeiro MG, Beserra IC, Guimaraes MM: Insulin resistance in adolescents with Down syndrome: a cross-sectional study. BMC Endocr Disord 2005, 5:1-6.

23. Bare MT, Waldron J, Gumm H, Van Dyke DC, Chang H: Nutrition assessment of the child with Down syndrome. In Clinical perspectives in the management of Down syndrome. Edited by Van Dyke DC, Lang DJ, Heide F, Van Duyne S, Soucek MJ. USA: Springer-Verlag New York Inc; 1990:107-25.

24. Magge SN, O'Neill KL, Shults J, Stallings VA, Stettler N: Leptin levels among prepubertal children with Down syndrome compared with their siblings. J Pediatr 2008, 152(3):321-6.

25. Steinbeck KS: Insulin resistance syndrome in children and adolescent: clinical meaning and indication for action. Int J Obesity 2004, 28:829-32.

26. Flore $P$, Bricout VA, Van Biesen $D$, Guinot $M$, Laporte F, Pépin JL, Eberhard $Y$, Favre-Juvin A, Wuyam B, van de Vliet P, Faure P: Oxidative stress and metabolism at rest and during exercise in persons with Down syndrome. Eur J Cardiovasc Prev Rehabil 2008, 15:35-42.

27. Martin SS, Qasim A, Reilly MP: Leptin resistance. A possible interface of inflammation and metabolism in obesity-related cardiovascular disease. JACC 2008, 52:1201-10.

28. Shaw CK, Thapalial A, Nanda S, Shaw P: Thyroid dysfunction in Down syndrome. KUMJ 2006, 4(2):182-6.

29. Kapelari K, Kirchlechner C, Högler W, Schweitzer K, Virgolini I, Moncayo R: Pediatric reference intervals for thyroid hormone levels from birth to adulthood: a retrospective study. BMC Endocr Disord 2008, 8:15.

30. Kupke IR, Tritschler W, Kather B, Bablk W: Creatine kinase NAC activated reference values for children. Klin Padiator 1980, 192(4):348-50

31. Clarkson PM, Hoffman EP, Zambraski E, Gordish-Dressman H, Kearns A, Hubal M, et al: ACTN3 and MLCK genotype associations with exertional muscle damage. J Appl Physiol 2005, 99:564-9.

32. Totsuka M, Nakaji S, Suzuki K, Sugawara K, Sato K: Break point of serum creatine kinase release after endurance exercise. J Appl Physiol 2002, 93:1280-6.

33. Ebbeling CB, Clarkson PM: Exercise-induced muscle damage and adaptation. Sports Med 1989, 7:207-34.

34. Gledhill RF, Van der merwe CA, Greyling TM, Van Niekerkt MM: Race-gender differences in serum creatine kinase activity: a study among South Africans. J of Neurology, Neurosurgery, and Psychiatry 1988, 51:301-304.

35. Pavlu J, Carey MP, Winer JB: Hypothyroidism and nemaline myopathy in an adult. J Neurol Neurosurg Psychiatry 2006, 77:708-9.

36. Kumar K, Guirgis M, Zieroth S, Lo E, Menkis AH, Arora RC, Freed DH: Influenza myocarditis and myositis: case presentation and review of the literature. Can J Cardiol 2011, 27:514-22.

37. Al Husain M: Body mass index for Saudi children with Down's syndrome. Acta Paediatric 2003, 92:1482-5. 
38. Lobstein T, Baur L, Uauy R: Obesity in children and young people: a crisis in public health. Obes Rev 2004, 5:4-10.

39. Freedman DS, Sherry B: The Validity of BMI as an indicator of body fatness and risk among children. Pediatrics 2009, 124(S 1):523-34.

40. González-Agüero A, Ara I, Moreno LA, Vicente-Rodríguez G, Casajús JA: Fat and lean masses in youths with Down syndrome: gender differences. Res Dev Disabil 2011, 32(5):1685-93.

41. Barlow SE: Expert committee recommendations regarding the prevention, assessment, and treatment of child and adolescent overweight and obesity: summary report. Pediatrics 2007, 120:s164-s92.

doi:10.1186/1472-6823-12-22

Cite this article as: Yahia et al.: Leptin, insulin and thyroid hormones in a cohort of Egyptian obese Down syndrome children: a comparative study. BMC Endocrine Disorders 2012 12:22.

\section{Submit your next manuscript to BioMed Central and take full advantage of:}

- Convenient online submission

- Thorough peer review

- No space constraints or color figure charges

- Immediate publication on acceptance

- Inclusion in PubMed, CAS, Scopus and Google Scholar

- Research which is freely available for redistribution 